\title{
An Experimental and Theoretical Study of the Coordination and Donor Properties of Tris-2-pyridyl-phosphine Ligands
}

Received 00th January 20xx, Accepted 00th January 20xx DOI: $10.1039 / x 0 x \times 00000 x$

\author{
Schirin Hanf,, annie L. Colebatch, ${ }^{a, b}$ Philipp Stehr, ${ }^{c}$ Raúl García-Rodríguez, ${ }^{d}$ Evamarie Hey- \\ Hawkins, ${ }^{* c}$ Dominic S. Wright*a
}

\begin{abstract}
The coordination characteristics and donor/acceptor propoerties of a series of 2-pyridyl substituted phosphine ligands have been investigated using structural, spectroscopic and DFT calculational studies. A range of different coordination modes are observed in Mo and W carbonyl complexes of tris-2-pyridyl-phosphine ligands of the type P(2-py') (2-py' = substituted or unsubstituted 2-pyridyl group), including an unprecendented example exhibiting $N, N^{\prime}, \mu_{2}-\pi$ coordination. DFT calculations were used to assess the relative donor/acceptor properties of a range of related 2-pyridyl-phosphine ligands with respect to $\mathrm{PPh}_{3}$ and $\mathrm{P}^{t} \mathrm{Bu}_{3}$
\end{abstract}

\section{Introduction}

A key aspect of the development of new single-site homogeneous transition metal catalysts is the way in which variation of the surrounding auxiliary ligand molecules can be used to modulate activity and selectivity. Within a given ligand class, it is therefore essential to evaluate the electronic and steric characteristics of the ligands carefully in order to be able to predict the impact of the ligand framework on the active transition metal centre site. ${ }^{1}$

One approach to determine the electronic (donor) properties of phosphines which are one of the most common classes of auxiliary ligands, is the Electronic Ligand Parameter (ELP, first established by W. Strohmeier in 1967). ${ }^{2}$ This describes the $\sigma$-donor and $\pi$-acceptor properties of a phosphine. Whereas $\sigma$-donation defines electron-donation from the $P$ lone pair into the empty metal $d$ orbitals, the $\pi$-accepting properties are related to the back-donation of electron density from the filled metal orbitals into the empty ligand orbitals ( $\sigma^{*}$ orbitals of the phosphine ligand). ${ }^{3}$ The ELP is based on the response of ligands (for instance $\mathrm{CO}$ ) to electronic changes on the metal centre caused by the coordination of the phosphine (Figure 1). ${ }^{2}$ In the case of $\mathrm{CO}$, greater $\sigma$-donor character of a bonded phosphine ligand leads to increased back donation of electron density to

a. Dr. S. Hanf, Dr. A. L. Colebatch, Prof. Dr. D. S. Wright, Chemistry Department, University of Cambridge, Lensfield Road, CB2 1EW, Cambridge, UK. E-mail: dsw1000@cam.ac.uk

b. Dr. A. L. Colebatch, Research School of Chemistry, Australian National University, Canberra, ACT 2601, Australia.

c. Dr. S. Hanf, P. Stehr, Prof. Dr. E. Hey-Hawkins, Institute of Inorganic Chemistry, Faculty of Chemistry and Mineralogy, Leipzig University, Johannisallee 29, 04103 Leipzig, Germany.E-mail: hey@uni-leipzig.de

d.Dr. R. García-Rodríguez, GIR MIOMeT-IU Cinquima-Química Inorgánica Facultad de Ciencias, Universidad de Valladolid, Campus Miguel, Delibes, 47011 Valladolid, Spain.

Electronic Supplementary Information (ESI) available. CCDC 1983662-1983667. For ESI and crystallographic data in CIF or other electronic format see DOI: $10.1039 / x 0 x x 00000 x$
$\mathrm{CO}$, with a resulting decrease in the CO bond energy and reduction of the $v_{\mathrm{CO}}$ in the IR spectrum, whereas increases $\pi$ acceptor character results in less back donation to $\mathrm{CO}$, higher CO bond energy and $v_{\text {co. }}$. Thus, measurement of $v_{\text {co }}$ in an isostructural model compounds can be used as a scale for the ELP.

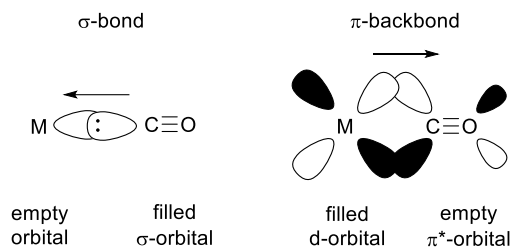

Figure 1: Molecular orbitals involved in the $\mathrm{M}-\mathrm{CO}$ coordinative bond. Left: $\sigma$ bonding from the filled $\sigma^{*}$ orbital of $\mathrm{CO}$, right: $\pi$-back bonding into the empty $\pi^{*}$ orbital of $\mathrm{CO}$

Later, C. A. Tolman devised the Tolman Electronic Parameter (TEP) from the IR spectra of $\left[\mathrm{Ni}(\mathrm{CO})_{3} \mathrm{~L}\right]$ complexes $(\mathrm{L}=$ phosphine ligand), using $\mathrm{P}^{t} \mathrm{Bu}_{3}$ as the reference ligand, due to its strong $\sigma$ donor character. ${ }^{4}$ For tertiary phosphines, the TEP is an empirical value and the correlation between the donor properties of the phosphine and the $\mathrm{CO}$ ligands (used as a probe for the electron density on the nickel centre) is illustrated in Equation 1, where $v_{\mathrm{CO}(\mathrm{Ni})}$ refers to the symmetric $\mathrm{A}_{1} \mathrm{CO}$ vibration of $\left[\mathrm{Ni}(\mathrm{CO})_{3} \mathrm{~L}\right], \quad 2056.1 \mathrm{~cm}^{-1}$ is the $\mathrm{A}_{1} \mathrm{CO}$ vibration of $\left[\mathrm{Ni}(\mathrm{CO})_{3}\left(\mathrm{P}^{t} \mathrm{Bu}_{3}\right)\right]$ and $\chi$ describes the effect of the phosphine ligand on the frequency of the $A_{1} C O$ stretch of the corresponding $\left[\mathrm{Ni}(\mathrm{CO})_{3} L\right]$ complex. ${ }^{4}$ The symmetric $A_{1}$ carbonyl stretching frequency of $\left[\mathrm{Ni}(\mathrm{CO})_{3} \mathrm{~L}\right]$ complexes is designated as the TEP and is given in $\mathrm{cm}^{-1}$.

$$
v_{\mathrm{CO}(\mathrm{Ni})}=2056.1 \mathrm{~cm}^{-1}+\Sigma \chi \quad \text { Eq. } 1
$$

The TEP has been shown to have a good linear correlation with the CO stretching frequencies of many other metal carbonyl complexes, incorporating tertiary phosphines (Equation 2, where $a$ and $b$ are linear coefficients). ${ }^{4-6}$ 


$$
v_{\mathrm{CO}(\text { Metal) }}=\mathrm{a} \cdot \mathrm{vCO}_{\mathrm{Ni}}+\mathrm{b} \quad \text { Eq. } 2
$$

Metal carbonyls worth mentioning in this context are based on vanadium, $^{2}$ chromium, ${ }^{2,7-10}$ molybdenum, ${ }^{2,5,8,9,11-14}$ tungsten, ${ }^{2,9,10,15-18}$ manganese, ${ }^{2,19,20}$ iron $^{2,21-27}$ and rhodium. ${ }^{21,28-30}$

Despite extensive interest in tris-2-pyridyl-phosphine ligands of the type $\mathrm{P}\left(2-\mathrm{py}^{\prime}\right)_{3} \quad\left(2-\mathrm{py}^{\prime}=\right.$ substituted or unsubstituted 2-pyridyl group) in coordination chemistry, materials and catalysis in the past few decades, ${ }^{31-34}$ no systematic studies have attempted to assess how the electronic character of ligands of this general class compares to other more commonly studied phosphine ligands. In this paper we show that most of the metal coordination modes known previously for tris-2-pyridyl-phosphine ligands (i.e., $\mathrm{K}^{3}-N, N^{\prime}, N^{\prime \prime}$, $\mathrm{K}^{2}-N, N^{\prime}, \mathrm{K}^{2}-P, N$ and $\mathrm{K}^{1}-P$ ) are found in their $\mathrm{W}$ and Mo carbonyl complexes. However, we also observe a new $\mu^{2}: \kappa^{1} P ; \kappa^{3} N, N^{\prime}, C, C^{\prime}$ bonding mode involving $\pi$-bonding of one of the 2-pyridyl groups to Mo which has never been reported previously. This complicated coordination chemistry limits the experimental determination of the Tolman Electronic Parameter (TEP) for the $\mathrm{K}^{1}-\mathrm{P}$. Overall assessment of the donor/acceptor properties of a larger series of 2-pyridyl-phosphine ligands was therefore achieved through DFT calculations. This study provides useful information which should be of value in the targeted design of homogeneous catalysts involving 2-pyridyl ligands.

\section{Results and Discussion}

\subsection{Experimental Determination of the Donor Properties of 2- Pyridyl-phosphines using $\mathbf{W}$ and Mo Carbonyl Complexes}

Due to the toxicity of the nickel tetracarbonyl precursor, the CO stretching frequencies of other metal carbonyl complexes incorporating tertiary phosphines, such as tungsten and molybdenum carbonyls, have been a topic of interest. ${ }^{5,6}$ The advantages of using molybdenum and tungsten carbonyl compounds for the determination of the TEP lies in their easy synthetic accessibility as well as the diamagnetic character of the $\mathrm{Mo}^{\circ} / \mathrm{W}^{0}$ carbonyl species, which enables facile NMR spectroscopic analysis. Therefore, 2-pyridyl-phosphines in the current study were reacted with tungsten(0) and molybdenum(0) carbonyl precursors to determine the $\mathrm{CO}$ stretching frequencies and the corresponding TEP. The investigated ligand sets are summarised in Figure 2 and their reactivity and coordination chemistry were recently explored within our group. ${ }^{35,36}$

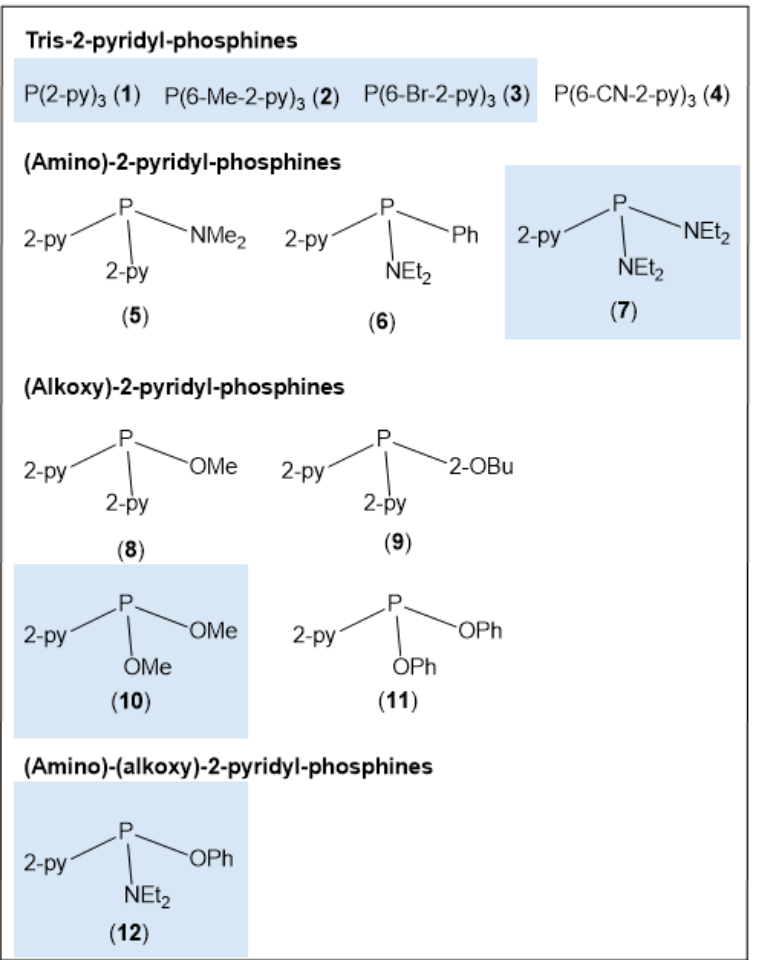

Figure 2: Selected 2-pyridyl-phosphines. Phosphines that were part of the coordination studies are marked in blue. Other phosphines have only been investigated computationally.

The reaction of tris-2-pyridyl-phosphine $\mathrm{P}(2-\mathrm{py})_{3}$ (1) with $\left[\mathrm{W}(\mathrm{CO})_{5}(\mathrm{MeCN})\right]$ in a $1: 1$ stoichiometric reaction resulted in the formation of a brown solution. After six days at room temperature ${ }^{31} \mathrm{P}\left\{{ }^{1} \mathrm{H}\right\}$ NMR spectroscopy in $\mathrm{CD}_{3} \mathrm{CN}$ at room temperature revealed full consumption of the free ligand and the presence of various phosphorus-containing tungsten complexes, probably resulting from the various possible coordination modes of the ligand (e.g. via the phosphorus as well as the nitrogen donor atoms). Layering a saturated DCM solution with $n$-hexane produced a mixture of dark red crystals of the tungsten tris-2-pyridyl-phosphine complex $\left[\mathrm{W}(\mathrm{CO})_{4}\{\mathrm{P}(2-\right.$ py) $\left.\left.{ }_{3}-K^{2} N, N^{\prime}\right\}\right](13)$ as well as colourless crystals of $\left[\mathrm{W}(\mathrm{CO}){ }_{4}\{\mathrm{P}(2-\right.$ py) $\left.\left.{ }_{3}-K^{1} P\right\}_{2}\right](14)$ (Scheme 1). In the ${ }^{31} P\left\{{ }^{1} H\right\}$ NMR spectrum of the crystalline mixture (in $\mathrm{CDCl}_{3}$ ), complex 13 is characterised by a

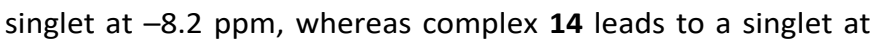
$33.5 \mathrm{ppm}$ with a ${ }^{1} J_{\mathrm{PW}}$ of $118.3 \mathrm{~Hz}$ (Figure S1 and S2). Despite attempts to optimise the formation of either complex using different reaction times, stoichiometries and reaction temperatures this reaction always led to a mixture of $\mathbf{1 3}$ and $\mathbf{1 4}$.

Within complex 13 , the tungsten atom is coordinated by two pyridyl-nitrogen atoms of one phosphine ligand in a cis arrangement and retains four carbonyl ligands. A similar complex, $\left[\mathrm{W} \equiv \mathrm{CPh}(\mathrm{CO})_{2} \mathrm{Cl}\left\{\mathrm{P}(2-\mathrm{py})_{3}-\mathrm{K}^{2} N, N^{\prime}\right\}\right]$, in which only two of the three pyridyl-nitrogen atoms are involved in the coordination to the tungsten centre was previously reported in the literature by C.-M. Che and co-workers. ${ }^{37}$ Complex 14 contains a tungsten centre that is coordinated by two phosphorus atoms of two ligand molecules and four carbonyl ligands. Unfortunately, since $\mathbf{1 3}$ and $\mathbf{1 4}$ could not be separated, no conclusions about the donor strength of the phosphine can be drawn from IR spectroscopy. However, very similar results 
were obtained from the reaction of $\left[\mathrm{Mo}(\mathrm{CO})_{4}(\mathrm{NBD})\right](\mathrm{NBD}=$ norbornadiene, bicyclo[2.2.1] hepta-2,5-diene) and $\mathrm{P}(2-\mathrm{py})_{3}$ or $\mathrm{PhP}(2-\mathrm{py})_{2}$. In-situ NMR and IR spectroscopic analyses have shown that initially, the $N, N^{\prime}$ - (analogous to 13) and the $P, P^{\prime}$ coordinated (analogous to 14) complexes are formed in equimolar amounts, but then the conversion of the $N, N^{\prime}$ - into the $P, P^{\prime}$-coordinated complex occurs. ${ }^{38,39}$

Attempts to employ the tris-2-pyridyl-phosphines $\mathrm{P}$ (6-Me-2$\mathrm{py}_{3}(2)$ and $\mathrm{P}(6-\mathrm{Br}-2-\mathrm{py})_{3}(3)$ or the (amino)- and (alkoxy)-2pyridyl-phosphines $\left(\mathrm{Et}_{2} \mathrm{~N}\right)_{2} \mathrm{P}(2-\mathrm{py})(\mathbf{7}),(\mathrm{MeO}){ }_{2} \mathrm{P}(2-\mathrm{py})(\mathbf{1 0})$ and $\left(\mathrm{Et}_{2} \mathrm{~N}\right)(\mathrm{PhO}) \mathrm{P}\left(2\right.$-py) (12) with $\left[\mathrm{W}(\mathrm{CO})_{5}(\mathrm{MeCN})\right]$ were unsuccessful, and only the tungsten precursor was isolated after workup. NMR spectroscopic analyses gave no clear indication of what kind of tungsten complexes had been formed. This is probably due to the presence of a variety of different donor atoms and dynamic complexation behaviour in solution.

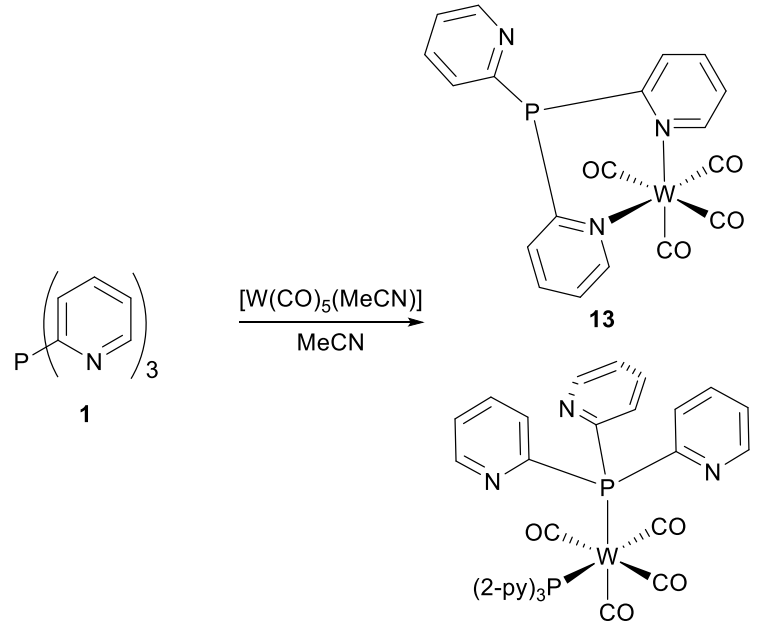

14

Scheme 1: Synthesis of tris-2-pyridyl-phosphine tungsten complexes 13 and 14

Similarly, the reaction of $\mathbf{2}$ with the $\mathrm{Mo}^{0}$ complex $\left[\mathrm{Mo}(\mathrm{CO})_{6}\right]$ gave mixtures of products which were difficult to separate. Heating $\left[\mathrm{Mo}(\mathrm{CO})_{6}\right]$ with $\mathbf{2}$ in $\mathrm{MeCN}$ at reflux overnight led to a number of resonances in the ${ }^{31} \mathrm{P}\left\{{ }^{1} \mathrm{H}\right\}$ NMR spectrum suggestive of complexes containing both $P$-coordinated (e.g. $\delta_{\mathrm{p}} 46.0 \mathrm{ppm}$ ) and $\mathrm{N}$-coordinated (e.g. $\delta_{\mathrm{p}} 0.2 \mathrm{ppm}$ ) phosphines. It was suspected that one of the observed $N$-coordinated species might be $\left[\mathrm{Mo}(\mathrm{CO})_{3}\left\{\mathrm{P}(6-\mathrm{Me}-2-\mathrm{py})_{3}-K^{3} N, N^{\prime}, N^{\prime \prime}\right\}\right]$ (15), which is known for 1, i.e. $\left[\mathrm{Mo}(\mathrm{CO})_{3}\left\{\mathrm{P}(2-\mathrm{py})_{3}-\mathrm{K}^{3} N, N^{\prime}, N^{\prime \prime}\right\}\right]{ }^{40}$ Reaction of 2 with $\left[\mathrm{Mo}(\mathrm{CO})_{3}(\mathrm{MeCN})_{3}\right]$ (generated in-situ) again yielded a mixture of compounds. Crystallisation from $\mathrm{DCM} / n$-hexane gave red crystals, which were identified by single crystal X-ray diffraction as the unusual bimetallic complex $\left[\mathrm{Mo}_{2}(\mathrm{CO})_{6}\{\mathrm{P}(6-\right.$ Me-2-py) $\left.\left.{ }_{3}-\mu^{2}: K^{1} P ; \kappa^{3} N, N^{\prime}, C, C^{\prime}\right\}\left\{\mathrm{P}(6-\mathrm{Me}-2-\mathrm{py})_{3}-\mathrm{K}^{2} P, N\right\}\right]$ (Scheme 2). Attempts to optimise the formation of $\mathbf{1 5}$ and $\mathbf{1 6}$ in these reactions using different reaction times, stoichiometries and reaction temperatures only led to mixtures.

In 16, one of the phosphine ligands 2 coordinates as a bidentate $P, N$-chelate to one of the metal centres, using the bridgehead $\mathrm{P}$ atom and one of the $\mathrm{N}$-atoms of a 2-py group. The other phosphine ligand acts as a bridging ligand by chelation of one of the Mo centres on one side and formation of a P-Mo bond to the other Mo atom on the other. Instead of the conventional $N, N^{\prime}, N^{\prime \prime}$ binding mode, this phosphine ligand adopts a highly unusual coordination mode in which two of the 2-py $\mathrm{N}$-atoms chelate the Mo atom while the other 2-py substituent is involved in $\eta^{2}-C, C^{\prime}$ coordination to the Mo atom. This coordination mode is unprecedented for tris-2-pyridyl ligands of any type but a $N, \eta^{2}-C, C^{\prime}$ coordination mode has been observed in one case for a complex of $\mathrm{Rh}^{\prime}$ with the bis-2-py pincer ligand $\left(\mathrm{CH}_{3}\right)_{2} \mathrm{C}(2-\mathrm{py})_{2} \cdot{ }^{41}$ Related examples involving other pincer ligands are also worthy of note. ${ }^{42,43}$

Unfortunately, 16 could not be isolated cleanly on a preparative scale, being present as a mixture with other unidentified species. In the hope of obtaining pure product, the reaction of 2 with $\left[\mathrm{Mo}(\mathrm{CO})_{3}\left(\eta^{6}-\mathrm{C}_{7} \mathrm{H}_{8}\right)\right]$ was investigated. However, mixtures of compounds were similarly observed, one of which was identified by X-ray crystallography as the monometallic complex $\left[\mathrm{Mo}(\mathrm{CO})_{3}\left\{\mathrm{P}(6-\mathrm{Me}-2-\mathrm{py})_{3}-\mathrm{K}^{3} N, N^{\prime}, N^{\prime \prime}\right\}\right]$ (15) in which 2 binds as a conventional $N, N^{\prime}, N^{\prime \prime}$ tripodal ligand (Scheme 2). Similar mixtures of products were obtained using a range of reaction conditions.

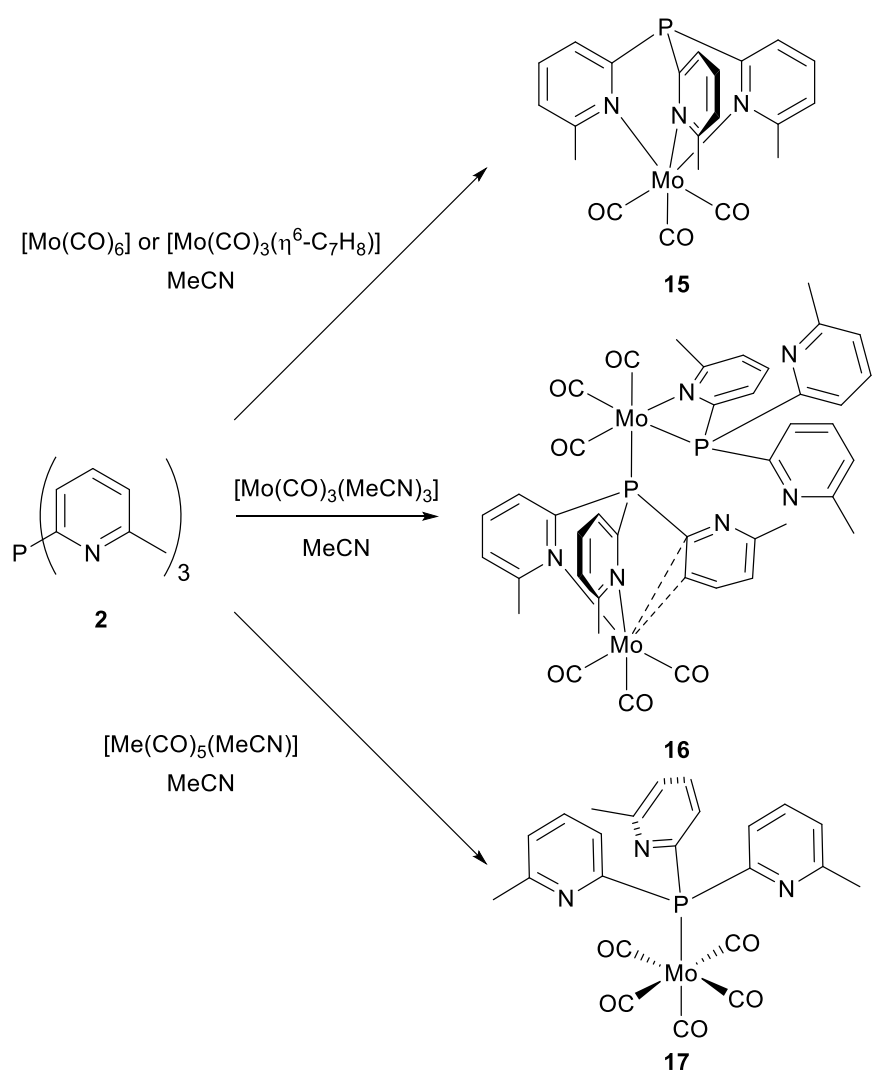

Scheme 2: Synthesis of tris-(6-methyl-2-pyridyl)-phosphine molybdenum complexes $\mathbf{1 5}$, 16 and 17.

Although neither $\mathbf{1 5}$ nor $\mathbf{1 6}$ could be cleanly isolated, they could be observed by ${ }^{31} \mathrm{P}\left\{{ }^{1} \mathrm{H}\right\}$ NMR spectroscopy of the isolated solids. In $\mathrm{CDCl}_{3}, 15$ appears as a singlet at $0.7 \mathrm{ppm}$, slightly downfield shifted relative to free ligand ( $-3.2 \mathrm{ppm}$, Figure S3). The nature of $\mathbf{1 6}$ in solution, however, appears to be solvent dependent. In $\mathrm{C}_{6} \mathrm{D}_{6}$, two doublet resonances are observed at 68.8 and $4.2 \mathrm{ppm}\left(J_{\mathrm{PP}}=23 \mathrm{~Hz}\right.$, Figure S4). In $\mathrm{CD}_{3} \mathrm{CN}$, these 
doublets shift to 43.5 and $-0.2 \mathrm{ppm}\left(J_{\mathrm{PP}}=24 \mathrm{~Hz}\right.$, Figure $\left.\mathrm{S} 5\right)$. The downfield resonance is consistent with $P$ coordination, whereas the upfield resonance corresponds to the $P, N$ ring, as seen in the only other example of tris-(2-pyridyl)-phosphine $P, N$ coordination to molybdenum found in $\left[\mathrm{MoBr}\left(\eta^{3}-\right.\right.$ $\left.\left.\mathrm{C}_{3} \mathrm{H}_{5}\right)(\mathrm{CO})_{2}\left\{\mathrm{P}(2-\mathrm{py})_{3}-\mathrm{K}^{2} \mathrm{P}, \mathrm{N}\right\}\right] \quad\left(\delta_{\mathrm{P}} \quad-10.0 \quad \mathrm{ppm}\right) .{ }^{44}$ Similar observations were made in $\mathrm{CDCl}_{3}$ (i.e. $67.5,3.1\left(J_{\mathrm{PP}}=24 \mathrm{~Hz}\right)$; 46.0, $\left.1.8\left(J_{\mathrm{PP}}=24 \mathrm{~Hz}\right)\right)$. Whether the $\mathrm{K}^{3}-N, N^{\prime}, C, C^{\prime}$ coordination mode is retained in solution is uncertain. The dramatic shift in the ${ }^{31} \mathrm{P}$ resonance of the bridging phosphine might be explained by $\mathrm{k}^{3}$ coordination in a non-coordinating solvent $\left(\mathrm{C}_{6} \mathrm{D}_{6}\right)$, which is disrupted by coordinating solvents $\left(\mathrm{CD}_{3} \mathrm{CN}\right.$, or partially for weakly coordinating $\mathrm{CDCl}_{3}$ ) that bind $\mathrm{Mo}$ in place of the weak $\eta^{2}-C, C^{\prime}$ interaction.

In light of the difficulties preparing tris-2-pyridyl-phosphine complexes of $\mathrm{Mo}^{0}$ cleanly, efforts were redirected to the precursor $\left[\mathrm{Mo}(\mathrm{CO})_{5}(\mathrm{MeCN})\right]$ as this might favour formation of the desired P-coordinated $\left[\mathrm{Mo}(\mathrm{CO})_{5} \mathrm{~L}\right]$ and circumvent formation of product mixtures with various coordination modes. The $\mathrm{Mo}^{0}$ complex $\left[\mathrm{Mo}(\mathrm{CO})_{5}\left\{\mathrm{P}(6-\mathrm{Me}-2-\mathrm{py})_{3}-\mathrm{K}^{1} \mathrm{P}\right\}\right]$ (17) was cleanly obtained from the reaction of $\mathbf{2}$ with $\left[\mathrm{Mo}(\mathrm{CO})_{5}(\mathrm{MeCN})\right]$ in acetonitrile at room temperature (Scheme 2). Crystals were grown by layering a DCM solution with $n$-hexane (crystalline yield: $18 \%$ ). The ${ }^{31} \mathrm{P}\left\{{ }^{1} \mathrm{H}\right\}$ spectrum of 17 contains a singlet, which is shifted downfield relative to the free ligand 2. In $\mathrm{CDCN}_{3} \mathbf{1 7}$ appears as singlet at $45.3 \mathrm{ppm}$ in the ${ }^{31} \mathrm{P}\left\{{ }^{1} \mathrm{H}\right\}$ NMR spectrum. 17 represents the first Mo complex in which a 2-pyridyl-phosphine coordinates to the Mo metal centre only via the $\mathrm{P}$ bridgehead. Other 2-pyridyl-phosphine Mo complexes usually involve $N, N^{\prime}, N^{\prime \prime}$-coordination, as seen in $\mathbf{1 5}$ and in the previously reported complex $\left[\mathrm{Mo}(\mathrm{CO})_{3}\left\{\mathrm{P}(2-\mathrm{py})_{3-}\right.\right.$ $\left.\left.\mathrm{K}^{3} \mathrm{~N}, \mathrm{~N}^{\prime}, N^{\prime \prime}\right\}\right],{ }^{40}$ or $P, N$-coordination, as found in $\mathbf{1 6}$ and trans$\left[\mathrm{Mo}_{2}\left(\mathrm{O}_{2} \mathrm{CCF}_{3}\right)_{4}\left\{\mathrm{P}(2-\mathrm{py})_{3}-\mu^{2}: \mathrm{K}^{2} P, N\right\}_{2}\right]{ }^{45}$ Since only $P$-coordination to the Mo centre occurs in 17, the IR spectrum of $\mathbf{1 7}$ can be used to obtain the TEP.

The reaction of tris-2-pyridyl-phosphine $\mathbf{1}$ with the in-situ generated $\left[\mathrm{Mo}(\mathrm{CO})_{5}(\mathrm{MeCN})\right]$ resulted in the formation of different $P$-containing species, which exhibited downfield as well as upfield shifted signals in the ${ }^{31} \mathrm{P}\left\{{ }^{1} \mathrm{H}\right\}$ NMR spectrum with respect to the free ligand. Different reaction conditions also gave mixtures of products. Layering a saturated DCM solution with $n$-hexane gave a few single-crystals of the literature-known Mo-complex $\left[\mathrm{Mo}(\mathrm{CO})_{3}\left\{\mathrm{P}(2-\mathrm{py})_{3}-\mathrm{k}^{3} N, N^{\prime}, N^{\prime \prime}\right\}\right](\mathbf{1 8})$, similar to 15 , in which the ligand binds the metal at the facial position of an octahedron via all three pyridyl-nitrogen atoms (Scheme 3). ${ }^{40}$ The upfield shift of the ${ }^{31} \mathrm{P}\left\{{ }^{1} \mathrm{H}\right\}$ NMR signal to $-4.3 \mathrm{ppm}$ in $\mathrm{CDCl}_{3}$ indicates that this $N, N^{\prime}, N^{\prime \prime}$-coordination is retained in solution.
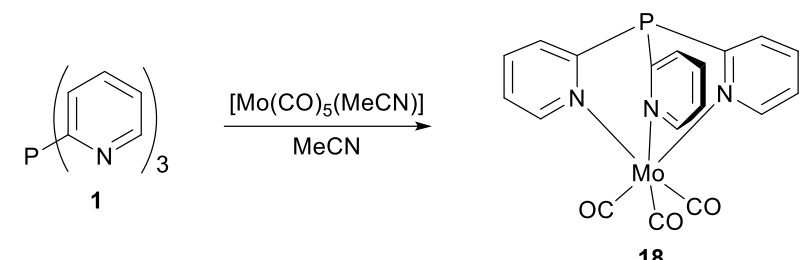

18

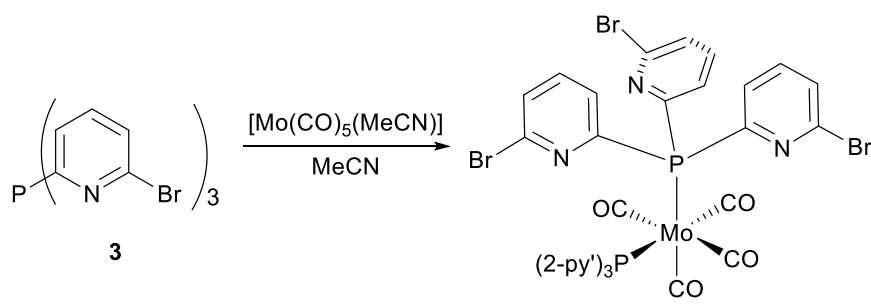

19, $\mathrm{P}\left(2-\mathrm{py}^{\prime}\right)_{3}=\mathrm{P}(6-\mathrm{Br}-2-\mathrm{py})_{3}$

Scheme 3: Synthesis of tris-2-pyridyl-phosphine molybdenum complexes 18 and Sche
19.

In the case of the reaction of the 6-Br-substituted tripodal phosphine 3 with $\left[\mathrm{Mo}(\mathrm{CO})_{5}(\mathrm{MeCN})\right]$, the disubstituted complex cis-[Mo(CO) $\left.{ }_{4}\left\{\mathrm{P}(6-\mathrm{Br}-2-\mathrm{py})_{3}-\mathrm{K}^{1} P\right\}_{2}\right]$ (19) was isolated as pale yellow crystals in $13 \%$ yield (Scheme 3 ). Interestingly, two ligand molecules, instead of one, coordinate to the metal via their phosphorus bridgehead atoms in a cis fashion. In the roomtemperature ${ }^{31} \mathrm{P}\left\{{ }^{1} \mathrm{H}\right\}$ NMR spectrum in $\mathrm{CDCl}_{3}$ a downfield shift to $50.3 \mathrm{ppm}$ with respect to the free ligand $3(-0.9 \mathrm{ppm}$, $\mathrm{CD}_{3} \mathrm{COCD}_{3}$ ) was again observed, similarly to that seen in complex 17.

Figure 3 shows the IR spectra of solid $\mathbf{1 7}$ and 19. In the case of $\mathbf{1 7}$ at least four carbonyl stretching bands in the range of $1913-2070 \mathrm{~cm}^{-1}$ are present whereas in the IR spectrum of 19 three carbonyl bands in the $1880-2030 \mathrm{~cm}^{-1}$ region are seen. For the evaluation of the donor strength, only the $A_{1}$ stretching bands at ca. $2067 \mathrm{~cm}^{-1}$ (for 17) and $2029 \mathrm{~cm}^{-1}$ (for 19), respectively, were used to evaluate the TEPs, owing to the overlapping and unresolved nature of the lower-energy bands. ${ }^{46}$ Due to the different numbers of coordinating $\mathrm{CO}$ and phosphine ligands and the thereof resulting different symmetry of 17 and 19, the $A_{1}$ stretching frequencies cannot be compared directly. Therefore, both $\mathrm{A}_{1} \mathrm{CO}$ vibrations are converted into the corresponding TEPs using empirical correlation equations.

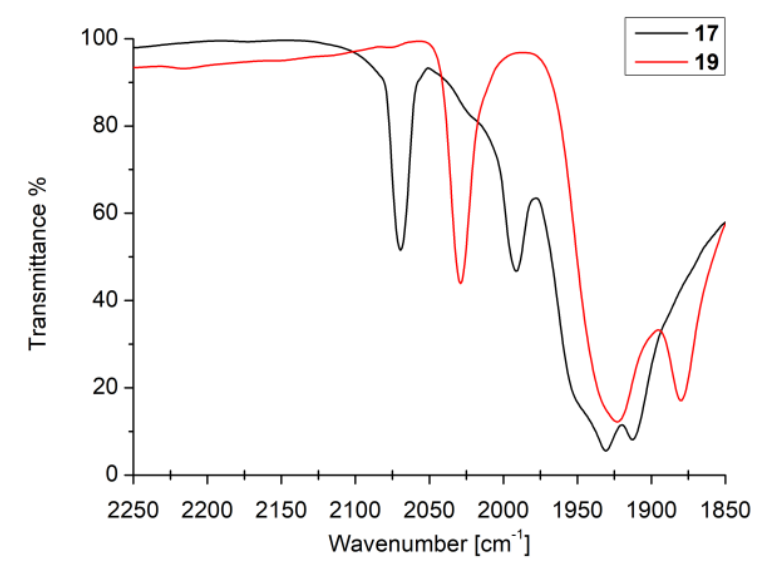


Figure 3: Extract of the IR spectra of complexes 17 and 19, measured as a $\mathrm{KBr}$ pellet in the solid-state.

Based on the correlation between the TEP and the experimentally measured data, the $A_{1} C O$ vibration in $\left[\mathrm{Mo}(\mathrm{CO})_{5} \mathrm{~L}\right]$ complexes can be converted into the TEP according to Equation $3 .^{6}$ From this equation, the $A_{1}$ stretch at $2070 \mathrm{~cm}^{-1}$ for complex 17 was calculated to correspond to an $A_{1}$ stretch of $2067 \mathrm{~cm}^{-1}$ in the corresponding nickel complex $\left[\mathrm{Ni}(\mathrm{CO})_{3}\{\mathrm{P}(6-\right.$ Me-2-py) 3$\}$ ].

$$
v \mathrm{CO}_{\mathrm{Ni}}=1.116 \cdot v \mathrm{CO}_{\mathrm{Mo}}-243(\mathrm{R}=0.858) \text { Eq. } 3
$$

For the conversion of the $A_{1} \mathrm{CO}$ stretch at approximately $2029 \mathrm{~cm}^{-1}$ in 19 into the corresponding Tolman parameter, the so-called Crabtree scale can be used. R. H. Crabtree showed that the carbonyl stretching frequency of cis-[Mo(CO) $\left.)_{4}(\mathrm{~L}-\mathrm{L})\right]$ complexes, in which $\mathrm{L}-\mathrm{L}$ can be a bidentate phosphine ligand or two monodentate phosphines, correlates very well $(R=0.996)$ with the TEP using Equation $4 .^{5}$

$$
v \mathrm{CO}_{\mathrm{Ni}}=0.593 \cdot \mathrm{vCO}_{\mathrm{Mo}}+871(\mathrm{R}=0.996) \text { Eq. } 4
$$

An $A_{1} v C O$ absorption at $2074 \mathrm{~cm}^{-1}$ was calculated for the corresponding nickel complex $\left[\mathrm{Ni}(\mathrm{CO})_{3}\left\{\mathrm{P}(6-\mathrm{Br}-2-\mathrm{py})_{3}\right\}\right]$; this frequency is slightly larger than the one calculated for $\left[\mathrm{Ni}(\mathrm{CO})_{3}\left\{\mathrm{P}(6-\mathrm{Me}-2-\mathrm{py})_{3}\right\}\right]$. This indicates decreased metal-CO back-bonding and a progressively stronger $\mathrm{C}-\mathrm{O}$ bond in the case of the $\mathrm{P}(6-\mathrm{Br}-2-\mathrm{py})_{3}$ ligand. Therefore, $\mathrm{P}(6-\mathrm{Br}-2-\mathrm{py})_{3}$ exhibits a lower net donor strength than $\mathrm{P}(6-\mathrm{Me}-2-\mathrm{py})_{3}$, which is plausible, since the introduction of electron-withdrawing substituents in the 6-position of the pyridyl rings, like the $\mathrm{Br}$ substituent, should lead to reduced $\sigma$-donor strength and enhanced $\pi$-acceptor capability. In comparison, the triphenylphosphine nickel complex $\left[\mathrm{Ni}(\mathrm{CO})_{3}\left(\mathrm{PPh}_{3}\right)\right]$ shows an $\mathrm{A}_{1}$ vCO absorption at $2070 \mathrm{~cm}^{-1}$. ${ }^{6}$ From this it can be concluded that $\mathbf{2}$ has a slightly higher net donor strength than $\mathrm{PPh}_{3}$, whereas the bromine-substituted ligand $\mathbf{3}$ comprises the lowest net donor strength, due to its better $\pi$-accepting properties.

\subsubsection{Solid-state structures of the $\mathbf{W}$ and Mo complexes}

The solid-state structures of the new tungsten(0) and molybdenum(0) complexes $\left[\mathrm{W}(\mathrm{CO})_{4}\left\{\mathrm{P}(2-\mathrm{py})_{3}-\mathrm{k}^{2} N, N^{\prime}\right\}\right] \cdot \mathrm{DCM}$ (13.DCM), cis- $\left[\mathrm{W}(\mathrm{CO})_{4}\left\{\mathrm{P}(2-\mathrm{py})_{3}-\mathrm{K}^{1} \mathrm{P}\right\}_{2}\right](14),\left[\mathrm{Mo}(\mathrm{CO})_{3}\{\mathrm{P}(6-\mathrm{Me}-2-\right.$ py) $\left.\left.{ }_{3}-\mathrm{K}^{3} N, N^{\prime}, N^{\prime \prime}\right\}\right] \quad(15), \quad\left[\mathrm{Mo}_{2}(\mathrm{CO})_{6}\left\{\mathrm{P}(6-\mathrm{Me}-2-\mathrm{py})_{3}-\right.\right.$ $\left.\left.\mu^{2}: K^{1} P ; \kappa^{3} N, N^{\prime}, C, C^{\prime}\right\}\left\{P(6-M e-2-p y)_{3}-\kappa^{2} P, N\right\}\right] \cdot D C M \quad$ (16-DCM), $\left[\mathrm{Mo}(\mathrm{CO})_{5}\left\{\mathrm{P}(6-\mathrm{Me}-2-\mathrm{py})_{3}-\mathrm{K}^{1} \mathrm{P}\right\}\right]$ (17) and cis-[Mo(CO) ${ }_{4}\{\mathrm{P}(6-\mathrm{Br}-2-$ py) $\left.\left.{ }_{3}-\mathrm{K}^{1} P\right\}_{2}\right](\mathbf{1 9} \cdot 2 n$-hexane) were determined by single-crystal $\mathrm{X}$ ray crystallography (ESI, Table S1 and S2).

Figure 4 depicts the crystal structure of the $\mathrm{W}^{0}$ complex $\left[\mathrm{W}(\mathrm{CO})_{4}\left\{\mathrm{P}(2-\mathrm{py})_{3}-\mathrm{K}^{2} N, N^{\prime}\right\}\right](13)$ present in the isolated crystalline solvate 13-DCM. The tris-2-pyridyl-phosphine 1 coordinates the tungsten centre using two of the three pyridyl-nitrogen donor atoms. The third pyridyl- $\mathrm{N}$ atom is not involved in any coordination in the solid state and points away from the metal. In addition, four carbonyl ligands coordinate to the tungsten centre, resulting in a distorted octahedral coordination environment. The $\mathrm{N}-\mathrm{W}-\mathrm{N}$ bond angles are in the range $82.07(8)-82.76(8)^{\circ}$ and are therefore considerably smaller than the ideal octahedral angle of $90^{\circ}$, due to the chelation of the $\mathrm{W}$ centre via the two nitrogen atoms of one ligand. The W-CO bond lengths in cis positions with respect to the $\mathrm{N}$-donor atoms of the ligand are in the range 2.032(3)-2.058(3) $\AA$ and therefore longer than the two $\mathrm{W}-\mathrm{CO}$ bond lengths in trans positions, which were found to be 1.953(3)-1.959(3) Å. For the $\mathrm{C}-\mathrm{O}$ bond lengths, the reverse trend is observed. The cis $\mathrm{C}-\mathrm{O}$ bond lengths (1.141(4)-1.151(4) A) are shorter than the trans ones (1.169(4)$1.172(4) \AA \AA$ ). This can be attributed to the trans-influence of the coordinated $\mathrm{N}$-atoms. ${ }^{47,48}$

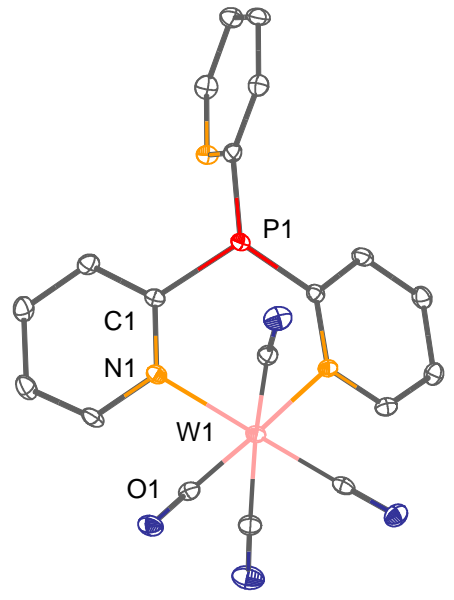

Figure 4: Structure of $\left[\mathrm{W}(\mathrm{CO})_{4}\left\{\mathrm{P}(2-\mathrm{py})_{3}-\mathrm{K}^{2} N, N^{\prime}\right\}\right] \cdot \mathrm{DCM}(13 \cdot \mathrm{DCM})$. Only one of the two molecules in the asymmetric unit is depicted. The DCM solvent molecule in
the lattice and hydrogen atoms are omitted for clarity. Displacement ellipsoids are drawn at the $30 \%$ probability level. Selected bond lengths $(\AA)$ and angles $\left({ }^{\circ}\right): W-N$ $2.268(2)-2.274(2)$, W-C 1.953(3)-2.058(3), C-O 1.141(4)-1.172(4), N-W-N 82.07 (8) -82.76 8), P-C 1.837(2)-1.848(4), P-C-N 112.0(2)-120.8(2), C-P-C 100.1(1)-103.7(1), N-W-N 82.07(8)-82.76(8).

The tungsten complex cis-[W(CO) $\left.{ }_{4}\left\{\mathrm{P}(2-\mathrm{py})_{3}-\mathrm{K}^{1} \mathrm{P}\right\}_{2}\right]$ (14) in which two ligand molecules are involved in the coordination via their $\mathrm{P}$ bridgeheads, is shown in Figure 5. In addition to the two phosphine molecules in cis positions, four $\mathrm{CO}$ groups coordinate the metal, resulting in a distorted octahedral coordination. Due to the steric clash between the phosphine ligands, the P-W-P angle is slightly widened $\left(98.77(2)^{\circ}\right)$. The $\mathrm{P}-\mathrm{W}$ bond lengths are in the range 2.5050(7)-2.5253(6) $\AA$ and the lengths of the W$\mathrm{CO}$ in cis position to the 2-py N-atoms are in the range 2.036(3)2.038(2) $\AA$ and therefore longer than the ones that are trans, which are in the range 1.975(3)-1.995(2) $\AA$, in accord with the trans-influence. The $\mathrm{C}-\mathrm{O}$ bond lengths found in $\mathbf{1 4}$ are $\mathrm{C}_{c i s}-\mathrm{O}$ $1.143(3)-1.146(4) \AA \AA$ and $C_{\text {trans }}-0$ 1.149(3)-1.162(3) A.

Interestingly, the cis/trans-isomerisation in diphenyl-2pyridyl-phosphine tungsten carbonyl complexes has been found to be affected by intramolecular, or more precisely intraligand, hydrogen bonding and pyridinium cation $\pi$-interactions, and can therefore be switched by the deliberate protonation or deprotonation of the 2-pyridyl-phosphine derivatives. ${ }^{49,50}$ The solid-state structure of $\mathbf{1 4}$ also shows a potential intramolecular face-to-face $\pi$-stacking interaction between the two pyridyl moieties of the two phosphine ligands, with the shortest distance between the rings being 3.617 (3) $\AA$ (C-C distance between ipso carbon atoms, Figure 5 right). However, since this potential $\pi$-interaction exceeds the sum of the van der Waals radii of the carbon atoms and there is significant tilting of the 2pyridyl rings (by $20.7^{\circ}$ ), it is unclear to what extent this could stabilise the formation of the unexpected cis-arrangement of 
the complex. The formation of the cis- rather than trans-isomer could simply arise for kinetic reasons, i.e., the phosphine ligand in a mono-substituted $\left[\mathrm{W}(\mathrm{CO})_{5}\left\{\mathrm{P}(2-\mathrm{py})_{3}-\mathrm{K}^{1} P\right\}\right]$ intermediate will strengthen the Mo-CO bond trans to it and slow the rate of substitution relative to the cis Mo-CO ligands.

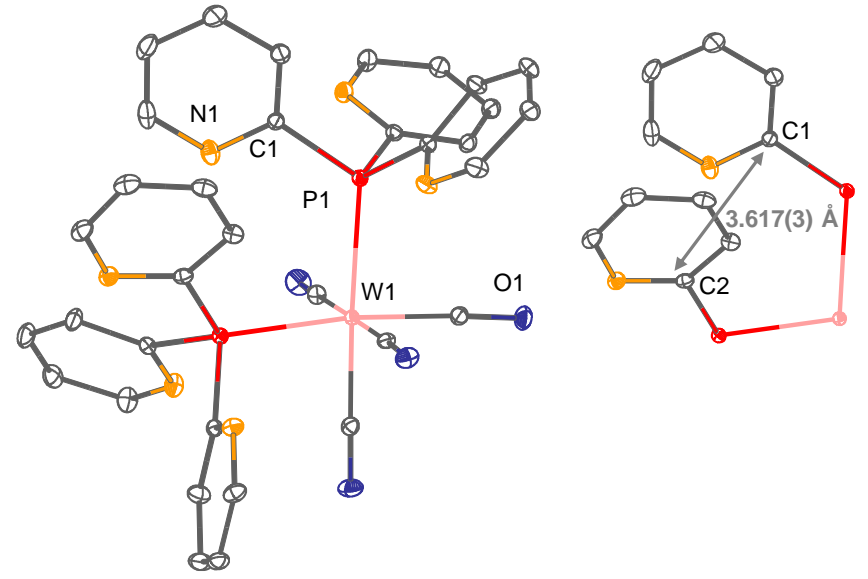

Figure 5: Structure of cis-[W(CO) $\left.{ }_{4}\left\{\mathrm{P}(2-\mathrm{py})_{3}-\mathrm{K}^{1} \mathrm{P}\right\}_{2}\right](\mathbf{1 4}$, left) and the potential faceto-face $\pi$-stacking interaction between the two pyridyl rings of the phosphine ligands (right). Hydrogen atoms are omitted for clarity. Displacement ellipsoids are drawn at the $30 \%$ probability level. Selected bond lengths $(\AA)$ and angles $\left({ }^{\circ}\right)$ : W-P
$2.5050(7)-2.5253(6), W-C$ W $1.975(3)-2.038(2)$, C-O 1.143(3)-1.162(3), P-C $1.843(2)-1.851(2), P-C-N 110.7(2)-118.0(2), C-P-C ~ 99.0(1)-109.1(1)$

The structure of $\left[\mathrm{Mo}(\mathrm{CO})_{3}\left\{\mathrm{P}(6-\mathrm{Me}-2-\mathrm{py})_{3}-\mathrm{K}^{3} N, N^{\prime}, N^{\prime \prime}\right\}\right](15)$ is shown in Figure 6. The geometry about Mo is distorted octahedral (angles 80.16(10)-96.91(8) ${ }^{\circ}$ ), similar to that observed in the previously reported compounds $\left[\mathrm{Mo}(\mathrm{CO})_{3}\{\mathrm{P}(2-\right.$ py) $\left.\left.)_{3}-K^{3} N, N^{\prime}, N^{\prime \prime}\right\}\right]^{40} \quad$ and $\quad\left[\mathrm{Mo}(\mathrm{CO})_{3}\left\{\mathrm{PhSi}(6-\mathrm{Me}-2-\mathrm{py})_{3^{-}}\right.\right.$ $\left.\left.\mathrm{K}^{3} N, N^{\prime}, N^{\prime \prime}\right\}\right] .{ }^{51}$ The Mo-N distances (2.3332(19)-2.3790(18) Å) are elongated compared to $\left[\mathrm{Mo}(\mathrm{CO})_{3}\left\{\mathrm{P}(2-\mathrm{py})_{3}\right\}-\mathrm{K}^{3} N_{,}, N^{\prime}, N^{\prime \prime}\right]$ (2.266(3)-2.282(3) $\AA$ ) , presumably as a result of steric demands of the 6-Me substituents in $\mathbf{1 5}$.

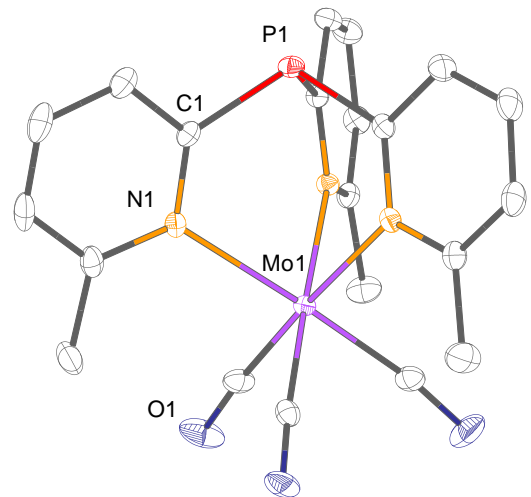

Figure 6: Structure of $\left[\mathrm{Mo}(\mathrm{CO})_{3}\left\{\mathrm{P}(6-\mathrm{Me}-2-\mathrm{py})_{3}-\mathrm{K}^{3} N_{,}, N^{\prime}, N^{\prime \prime}\right\}\right]$ (15). Hydrogen atoms are omitted for clarity. Displacement ellipsoids are drawn at the $30 \%$ probability level. Selected bond lengths $(\AA)$ and angles $\left({ }^{\circ}\right)$ : Mo-N 2.333(2)-2.379(2), Mo-C 1.929(3)1.942(3), C-O 1.168(3)-1.174(3), P-C 1.830(2), P-C-N 122.6(2)-124.5(2), C-P-C 102.0(1)-105.1(1), N-Mo-N 86.52(6)-86.82(6).

The crystal structure of the dinuclear complex $\left[\mathrm{Mo}_{2}(\mathrm{CO})_{6}\left\{\mathrm{P}(6-\mathrm{Me}-2-\mathrm{py})_{3}-\mu^{2}: K^{1} P ; K^{3} N, N^{\prime}, C, C^{\prime}\right\}\left\{\mathrm{P}(6-\mathrm{Me}-2-\mathrm{py})_{3}-\right.\right.$ $\left.\left.K^{2} P, N\right\}\right]$ (16) is shown in Figure 7. The Mo-P bond linking the two $\left[\mathrm{Mo}\left\{\mathrm{P}(6-\mathrm{Me}-2-\mathrm{py})_{3}\right\}\right]$ subunits of the arrangement together (Mo2-P1 2.5132(9) $\AA$ ) is longer than that seen in the $K^{1}-P$ coorination in mononuclear $17(2.5064(6) \AA$ ) (see later discussion). This could result from reduction of the donor character of the P-atom in this fragment or from the distinctly more sterically crowded arrangement of $\mathbf{1 6}$. The other P(6-Me2-py $)_{3}$ ligand acts as a $P, N$-chelate, forming a 4-membered metallocycle. The Mo2-P2 bond length 2.5801(9) A within this ring unit is elongated relative to Mo2-P1 and the Mo-P bond in 16, whereas the associated Mo2-N4 distance within the chelate (2.309(3) $\AA$ ) is within the range of Mo-N bond lengths observed at $\operatorname{Mo1}(2.298(3)-2.347(3) \AA)$.

The presence of a $\eta^{2}-C \cdots C \pi$-interaction involving $C 13 / C 14$ and Mo1 in 16 is indicated by the twisting of the associated 2py ring unit away from the normal pyridyl-N coordination mode found in tris-2-py ligands. The Mo1-C13 (2.558(4) Å) and Mo1C14 (2.680(4) $\AA$ ) distances are relatively long, indicating a weak interaction compared to olefin complexes (e.g. [Mo(CO) $\left.)_{4}(\mathrm{COD})\right]$ 2.462(6)-2.497(6) $\AA$ ), $, \mathrm{COD}=1,5$-cyclooctadiene). ${ }^{52}$ Evidence for the disruption of the aromaticity of the N3-pyridyl ring is suggested by the alternating $\mathrm{C} \cdots \mathrm{C}$ bond lengths (C13-C14 1.381(6), C14-C15 1.412(6), C15-C16 1.351(7), C16-C17 1.413(6), C17-N3 1.325(5), N3-C13 1.379(5) Å). However, it should be noted that this pattern is not necessarily significant, on the basis of the crystallographic errors. The presence of this $\eta^{2}-C \cdots C \pi$-interaction nonetheless retains the $18 \mathrm{e}$ count of Mo1.

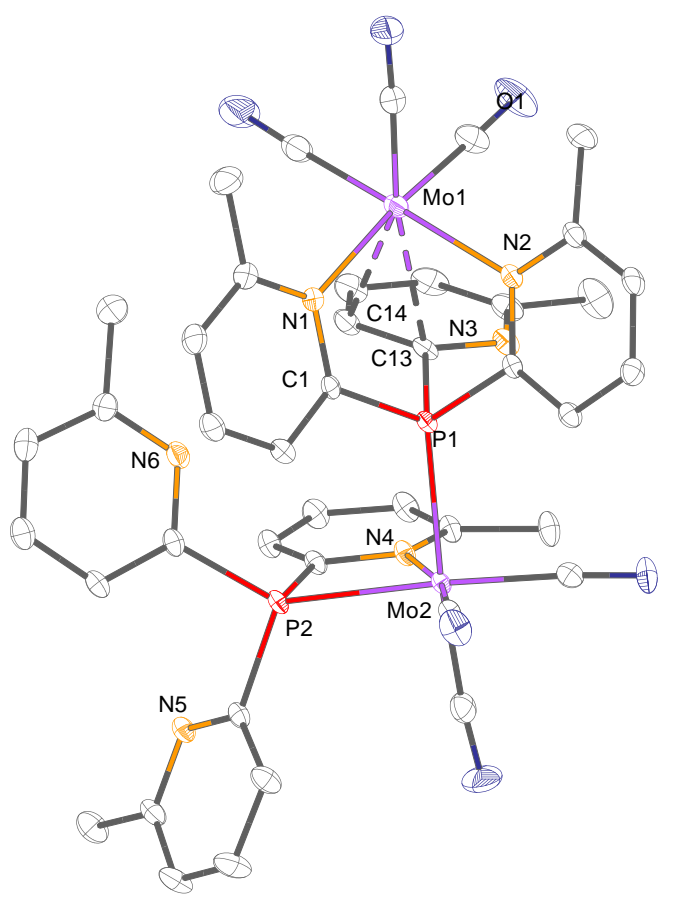

Figure 7: Structure of $\left[\mathrm{Mo}_{2}(\mathrm{CO})_{6}\left\{\mathrm{P}(6-\mathrm{Me}-2-\mathrm{py})_{3}-\mu^{2}: K^{1} P ; K^{3} N, N^{\prime}, C, C^{7}\right\}\left\{\mathrm{P}(6-\mathrm{Me}-2-\mathrm{py})_{3}\right.\right.$ $\left.\left.\mathrm{K}^{2} P, N\right\}\right] \cdot \mathrm{DCM}$ (16.DCM). The DCM solvent molecule and hydrogen atoms are omitted for clarity. Displacement ellipsoids are drawn at the $30 \%$ probability level. Selected bond lengths ( $\AA$ ) and angles $\left({ }^{\circ}\right)$ : Mo1-N 2.298(3)-2.347(3), Mo2-P1 2.5132(9), Mo2-P2 2.580(1), Mo1- $C_{\text {co }} 1.922(5)-1.948(5)$, Mo2- $C_{\text {co }} 1.945(5)-1.984(5)$, Mo1-C13 2.558(4), Mo1-C14 2.680(4), C-O 1.140(7)-1.169(6), P-C 1.827(4)-1.844(4), P-C-N 112.9(3)119.1(3), C-P-C 97.9(2)-106.3(2), P1-Mo2-P2 94.66(3).

In 17 (Figure 8), the $\mathrm{P}(6-\mathrm{Me}-2-\mathrm{py})_{3}$ ligand (2) bonds to the Mo centre using the softer, bridgehead P-atom (Mo-P 2.5064(6) $\AA$ ), resulting in a distorted octahedral coordination environment for the $\mathrm{Mo}^{0}$ centre in which the other five 
positions are occupied by CO ligands. The Mo-P bond length is shorter than in the previously reported triphenylphosphine counterpart $\left[\mathrm{Mo}(\mathrm{CO})_{5}\left(\mathrm{PPh}_{3}-\mathrm{K}^{1} \mathrm{P}\right)\right]\left(2.560(1) \AA^{53}\right)$. No detailed conclusions about the $\sigma$-donating and $\pi$-accepting properties of 2 compared to $\mathrm{PPh}_{3}$ can be drawn from analysis of the crystallographic data as the $\mathrm{C}-\mathrm{O}$ bond lengths in $\mathbf{1 6}$ and $\left[\mathrm{Mo}(\mathrm{CO})_{5}\left(\mathrm{PPh}_{3}-\mathrm{K}^{1} \mathrm{P}\right)\right]$ are the same within the crystallographic errors. ${ }^{53}$

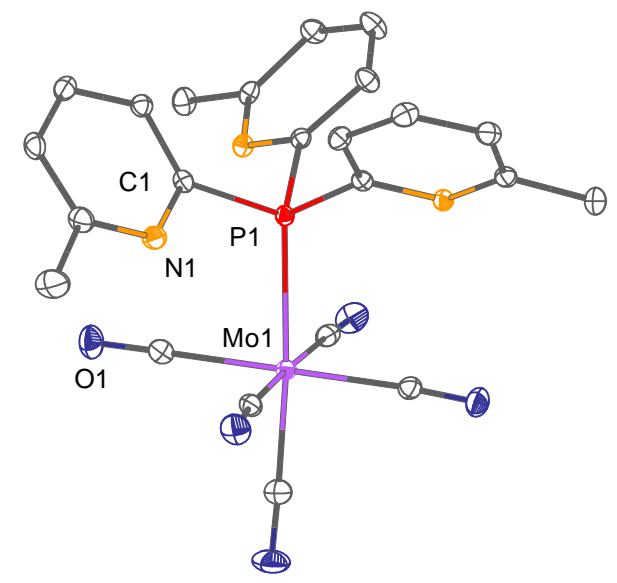

Figure 8: Structure of $\left[\mathrm{Mo}(\mathrm{CO})_{5}\left\{\mathrm{P}(6-\mathrm{Me}-2-\mathrm{py})_{3}-\mathrm{K}^{1} \mathrm{P}\right\}\right]$ (17). Hydrogen atoms are omitted for clarity. Displacement ellipsoids are drawn at the $30 \%$ probability level. Selected bond lengths (Å) and angles ( $\left.{ }^{\circ}\right)$ : Mo-P 2.5064(6), Mo-C 2.001(2)$2.061(2), \quad C-O \quad 1.136(3)-1.145(3), \quad P-C$ 1.835(2)-1.838(2), P-C-N 111.8(1)113.1(1), C-P-C 101.74(8)-103.01(8).

The structure of cis-[Mo(CO) $\left.{ }_{4}\left\{\mathrm{P}(6-\mathrm{Br}-2-\mathrm{py})_{3}-\mathrm{K}^{1} \mathrm{P}\right\}_{2}\right](\mathbf{1 9})$ is shown in Figure 9. Two bromo-substituted tris-2-pyridyl-phosphine ligands (3) coordinate the metal using their phosphorus bridgeheads (Mo-P 2.493(1)-2.5290(8) Å), in addition to four carbonyl ligands. These Mo-P bond lengths are shorter than those found in the previously reported counterpart cis$\left[\mathrm{Mo}(\mathrm{CO})_{4}\left(\mathrm{PPh}_{3}-\mathrm{K}^{1} \mathrm{P}\right)_{2}\right]\left(2.576(2)-2.577(2) \AA^{54}\right)$. As in the case of 14 , the cis isomer alone is present. This may again result at least in part from the presence of potential intramolecular $\pi-\pi$ interactions between the pyridyl rings of the two phosphine ligands, with the distance between the ipso carbon atoms of the two pyridyl rings involved being 3.354(4) $\AA$ and the two 2-py ring units being tilted by only $5.29^{\circ}$ with respect to each other. Again, as seen in all of the other complexes described above, the Mo-CO bond lengths at the cis positions with respect to both phosphine ligands are longer $(2.010(4)-2.071(4) \AA)$ than those that are trans $(1.987(3)-1.988(5) \AA \AA)$. The cis- and trans$\mathrm{C}-\mathrm{O}$ bonds are identical within the crystallographic errors and similar to those found previously in cis- $\left[\mathrm{Mo}(\mathrm{CO})_{4}\left(\mathrm{~K}^{1}-\mathrm{P}-\mathrm{PPh}_{3}\right)_{2}\right] .{ }^{54}$

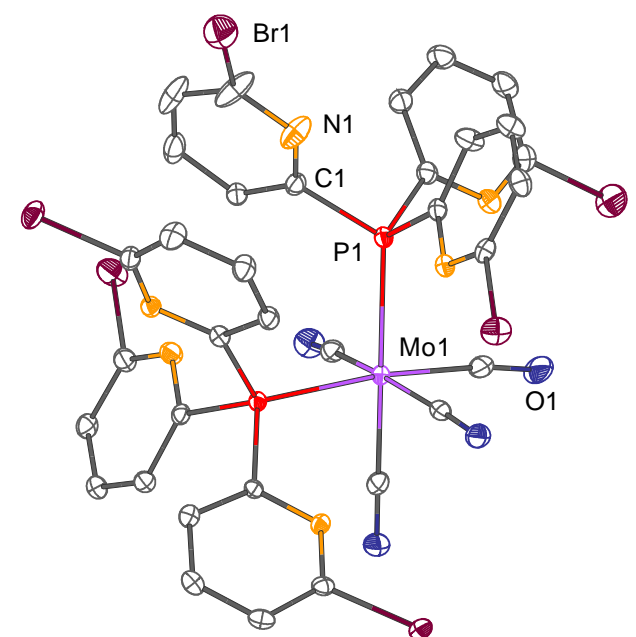

Figure 9: Structure of cis-[Mo(CO) $\left.{ }_{4}\left\{\mathrm{P}(6-\mathrm{Br}-2-\mathrm{py})_{3}-\kappa^{1} \mathrm{P}\right\}_{2}\right] \cdot 2 n$-hexane $(19 \cdot 2 n$ hexane). Hydrogen atoms, solvent molecules and the split valence of one of the $\mathrm{Br}$ atoms are omitted for clarity. Displacement ellipsoids are drawn at the $30 \%$ probability level. Selected bond lengths (A) and angles $\left(^{\circ}\right)$ : Mo-P 2.493(1) $2.5290(8)$, Mo-C 1.987(3)-2.071(4), C-O 1.128(5)-1.156(4), P-C $1.835(3)$ $1.853(3), \mathrm{P}-\mathrm{C}-\mathrm{N} 112.7(6)-120.9(2), \mathrm{C}-\mathrm{P}-\mathrm{C}$ 97.2(2)-105.2(1).

As seen in the case of the reactions with tungsten carbonyl, no pure products could be isolated from the reactions of the (amino)- and (alkoxy)-2-pyridyl-phosphines 7, 10 and 12 with $\mathrm{Mo}(0)$, despite several purification and crystallisation attempts. However, in all cases downfield shifts of the singlets in the ${ }^{31} \mathrm{P}\left\{{ }^{1} \mathrm{H}\right\} \quad N M R$ spectra were observed, suggesting that coordination via the phosphorus atoms probably occurred (Figure S17-S19).

\subsection{Calculation of the Tolman Electronic Parameters of 2-Pyridyl- phosphines}

Since the experimental determination of the TEP of 2-pyridylphosphines from $\mathrm{W}$ and Mo carbonyl complexes has proven to be difficult due to the presence of a variety of different donor atoms and the resulting different coordination motifs, DFT calculations were utilised to evaluate their net donor abilities. The great advantage of using accurate DFT methods is that a variety of ligands can be assessed in a short amount of time. ${ }^{1,55}$

Geometry optimisations and frequency analyses of nickel carbonyl complexes of the form $\left[\mathrm{Ni}(\mathrm{CO})_{3} \mathrm{~L}\right](\mathrm{L}=$ phosphine) were carried out employing the TPSS ${ }^{56}$ functional in conjunction with the def2-TZVP ${ }^{57,58}$ basis set (ESI, Table S3). In these complexes, coordination only via the phosphorus bridgehead atom is assumed. To define a spectrochemical series, the calculated symmetric $A_{1}$ carbonyl stretching frequencies of the nickel complexes were examined, and the tri-tert-butylphosphine and triphenylphosphine complexes were used as reference points (Figure 10).

All of the optimised nickel complexes show red-shifted symmetric carbonyl stretching frequencies in comparison to free CO $\left(2143 \mathrm{~cm}^{-1}\right)$. This is also accompanied by larger $\mathrm{C}-\mathrm{O}$ bond lengths with respect to free $\mathrm{CO}(1.128 \AA)$ and indicates a weakening of the $\mathrm{C}-\mathrm{O}$ bond. However, there are only very small deviations in the $\mathrm{C}-\mathrm{O}$ bond lengths, whereas the $v_{\text {co }}$ values are more wide-ranging. 


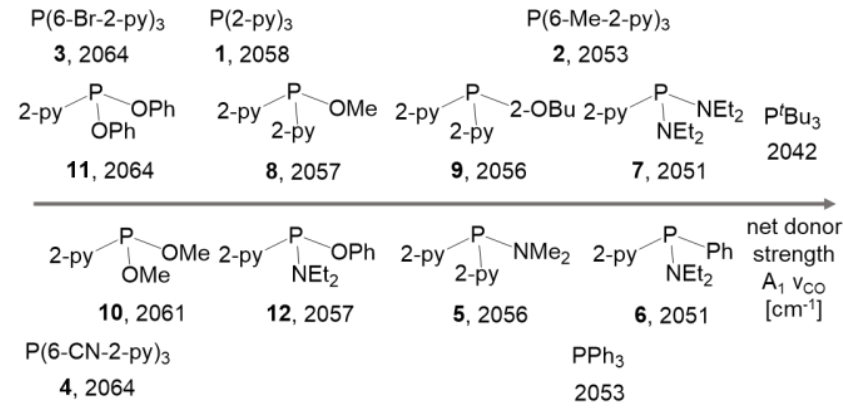

Figure 10: Calculated symmetric $A_{1} C O$ stretching vibrations of a range of complexes $\left[\mathrm{Ni}(\mathrm{CO})_{3} \mathrm{~L}\right]$ containing various 2-pyridyl-phosphine ligands (in $\mathrm{cm}^{-1}$. The points.

Since the Tolman electronic parameter represents the overall donor ability of a ligand, which consists of the $\sigma$-donor minus the $\pi$-acceptor contributions, conclusions can be made about the donor nature of the ligand. From the DFT calculations, it is obvious that the $\mathrm{Ni}$ carbonyl complexes of 2-pyridylphosphines incorporating electron-withdrawing substituents in the 6-position of the pyridyl groups, such as ligands $\mathbf{3}$ and $\mathbf{4}$, exhibit the highest $v_{C O}$ values and therefore the smallest net donor strength compared to the other phosphines. This finding indicates that $\mathbf{3}$ and $\mathbf{4}$ are poorer $\boldsymbol{\sigma}$-donors and exhibit greater $\pi$-accepting character, which would make them better coordination partners for electron-rich metals.

The nickel carbonyl complexes of the bis(alkoxy)-substituted 2-pyridyl-phosphines $\mathbf{1 0}$ and $\mathbf{1 1}$ show very similar symmetric carbonyl stretching frequencies to those calculated for the tris2-pyridyl-phosphine complexes $\left[\mathrm{Ni}(\mathrm{CO})_{3}\left\{\mathrm{P}(6-\mathrm{Br}-2-\mathrm{py})_{3}\right\}\right]$ and $\left[\mathrm{Ni}(\mathrm{CO})_{3}\left\{\mathrm{P}(6-\mathrm{CN}-2-\mathrm{py})_{3}\right\}\right]$. Again, the relatively low overall donor ability of $\mathbf{1 0}$ and $\mathbf{1 1}$ can most likely be attributed to the presence of two electron-withdrawing alkoxy substituents within the ligand sets, which lead to a reduction in the energy of the $P-R$ $\sigma^{*}$ orbitals, allowing more efficient metal-phosphine backbonding.

The incorporation of amino groups into the ligand framework, for example when comparing $\mathbf{1 1}$ to $\mathbf{1 2}$, results in a red shift of the $v_{c O}$ and therefore an increase in the net donor ability. The same effect can be observed for ligands with two pyridyl substituents rather than one. While $\left[\mathrm{Ni}(\mathrm{CO})_{3}\left\{(\mathrm{MeO})_{2} \mathrm{P}(2-\right.\right.$ py)\}] exhibits a $v_{\mathrm{CO}}$ of $2061 \mathrm{~cm}^{-1}$, the $\mathrm{A}_{1} \mathrm{CO}$ stretching frequency of $\left[\mathrm{Ni}(\mathrm{CO})_{3}\left\{(\mathrm{MeO}) \mathrm{P}(2-\mathrm{py})_{2}\right\}\right]$ was calculated to be $2057 \mathrm{~cm}^{-1}$. Similarly, the introduction of electron-donating groups in the 6position of the pyridyl moiety, such as in the case of $\mathbf{2}$, leads to enhanced donor strength of the phosphine. The net donor ability of ligand $\mathbf{2}$ is therefore comparable with that of triphenylphosphine.

One of the highest net donor strengths among the investigated 2-pyridyl-phosphine ligands was found for the bis(amino)-2-pyridyl-phosphine 7. This finding can be explained by its reduced $\pi$-accepting properties, since $\pi$-donation from the nitrogen lone pair into the $\mathrm{P}-\mathrm{N}^{\prime} \sigma^{*}$ orbital competes with back-donation from the metal centre to the phosphine. ${ }^{55}$

Not surprisingly, the smallest symmetrical CO stretching frequency of the nickel carbonyl complexes is found for $\mathrm{P}^{t} \mathrm{Bu}_{3}$. The very high net donor strength of the trialkyl-phosphine is due to the fact that the phosphine acts almost exclusively as a $\sigma$ donor, with little $\pi$-accepting ability.

\section{Conclusions}

In order to quantify the donor properties of various 2-pyridylphosphines, tungsten and molybdenum complexes were synthesised. However, the assessment of the donor properties of the metal complexes was not straightforward due to the multidentate character of the phosphines and their ability to adopt different coordination modes, including an unprecedented example of a $\mathrm{K}^{3}-N, N^{\prime}, C, C^{\prime}$ binding mode. Although parameters, such as the reaction time, solvents, stoichiometry and reaction temperature were explored in detail, in most cases only mixtures of inseparable products could be obtained. Therefore, the donor properties could only be assessed directly for two Mo complexes containing exclusively P-metal bonding, $\mathbf{1 7}$ and 19. From the conversion of the carbonyl stretching frequency into the corresponding Tolman parameter, it is clear that $\mathrm{P}(6-\mathrm{Me}-2-\mathrm{py})_{3}(2)$ has a higher net donor strength than $\mathrm{P}(6-\mathrm{Br}-2-\mathrm{py})_{3}$ (3). This is explained simply by the electron-withdrawing ability of the $6-\mathrm{Br}$ group compared to 6-Me.

In addition to the experimental work, the Tolman electronic parameters of twelve different 2-pyridyl-phosphines were calculated, along with those of $\mathrm{P}^{t} \mathrm{Bu}_{3}$ and $\mathrm{PPh}_{3}$ as reference points. The Tolman parameter proved valuable for the investigation of the overall donor properties of phosphines and, by computing this parameter, many synthetic limitations could be avoided. The calculated TEPs confirmed the conclusions drawn from the synthesised Mo complexes, and showed that the introduction of substituents into the 6-position of tris-2pyridyl-phosphines has a considerable effect on the overall donor properties of the phosphine.

This study offers the possibility for the evaluation of the donor properties of a variety of 2-pyridyl-phosphines with respect to triphenylphosphine and therefore lays the foundation for targeted ligand design for homogenous transition metal catalysts. It also shows that small alterations within the 2-pyridyl-phosphine scaffold can tailor the electronic properties drastically.

\section{Experimental Details}

All experiments were carried out on a Schlenk-line under a dry, oxygen-free nitrogen atmosphere and with the aid of a $\mathrm{N}_{2}$-filled glove box (MBraun lab star 50 or Saffron type $\alpha$ ). All solvents were freshly distilled over appropriate drying agents under nitrogen or taken from a solvent purification system (SPS-800, MBraun). Solvents were subsequently stored over molecular sieves. Deuterated solvents were dried over $\mathrm{P}_{2} \mathrm{O}_{5}$ or $\mathrm{CaH}_{2}$, when necessary, or over molecular sieves. The 2-pyridyl-phosphine ligands were synthesised according to literature procedures. ${ }^{35,36}$ NMR spectra were recorded on a Bruker Avance DRX 400, a $400 \mathrm{MHz}$ Avance III HD Smart Probe Spectrometer, a $400 \mathrm{MHz}$ Avance III HD Spectrometer or a 
Bruker Avance III HD $500 \mathrm{MHz}$ Smart Probe spectrometer at room temperature $(298 \mathrm{~K})$. All spectra were recorded in dry $\mathrm{CDCl}_{3}, \mathrm{CD}_{3} \mathrm{COCD}_{3}, \mathrm{CD}_{3} \mathrm{CN}, \mathrm{C}_{6} \mathrm{D}_{6}, \mathrm{D}_{8}$-THF or $\mathrm{D}_{8}$-tol with $\mathrm{SiMe}_{4}\left({ }^{1} \mathrm{H}\right)$ as an internal standard. ${ }^{1} \mathrm{H}$ and ${ }^{13} \mathrm{C}$ NMR spectra were referenced to TMS, whereas all other heteronuclei were referenced to TMS via the $\equiv$ scale. ${ }^{59}$ Unambiguous assignments of the NMR resonances were made on the basis of 2D NMR experiments $\left({ }^{1} \mathrm{H}-{ }^{1} \mathrm{H}\right.$ COSY and ${ }^{1} \mathrm{H}_{-13}{ }^{13} \mathrm{C} \mathrm{HMBC}$ experiments). Figure 11 shows the labelling scheme for the NMR assignments used in the experimental section. HR ESI MS measurements were carried out in positive ion mode using electrospray ionisation on a Bruker Impact II. IR measurements of the $\mathrm{KBr}$ pellets were obtained using a Perkin Elmer FT IR Spectrum 2000. Additional experimental details can be found in the ESI.

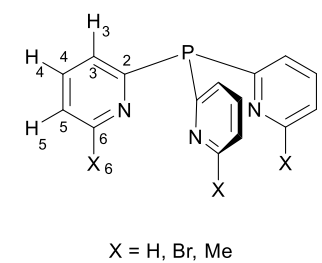

Figure 11: Atom labelling scheme used in the NMR studies for the 2-pyridylphosphine ligands.

\section{Synthesis of $\left[\mathrm{Mo}(\mathrm{CO})_{5}\left\{\mathrm{P}(6-\mathrm{Me}-2-\mathrm{py})_{3}-\mathrm{K}^{1} \mathrm{P}\right\}\right](17)$}

$\mathrm{Me}_{3} \mathrm{NO}(24 \mathrm{mg}, 0.33 \mathrm{mmol})$ and $\left[\mathrm{Mo}(\mathrm{CO})_{6}\right](86 \mathrm{mg}, 0.33 \mathrm{mmol})$ were dissolved in $8 \mathrm{ml}$ of acetonitrile and stirred for $30 \mathrm{~min}$ at room temperature. $2(0.10 \mathrm{~g}, 0.33 \mathrm{mmol})$ in $3 \mathrm{ml}$ of acetonitrile was added to this resulting bright yellow solution. Stirring for 3 days led to an orange brown suspension. The precipitate was filtered off, resulting in a red brown solution. Crystals could be obtained from the acetonitrile solution at $-25^{\circ} \mathrm{C}$. Crystalline yield: $33 \mathrm{mg}, 0.61 \mathrm{mmol}, 18 \% .{ }^{1} \mathrm{H}$ NMR $\left(\mathrm{CD}_{3} \mathrm{CN}, 400.16 \mathrm{MHz}\right), \delta$ [ppm] $=7.53\left(3 \mathrm{H}, \mathrm{td}, J_{\mathrm{HH}}=7.8 \mathrm{~Hz}, 3.3 \mathrm{~Hz}, \mathrm{H} 4\right), 7.18\left(3 \mathrm{H}, \mathrm{dd}, J_{\mathrm{HH}}=\right.$ $7.9 \mathrm{~Hz}, 2.5 \mathrm{~Hz}, \mathrm{H} 5), 6.93\left(3 \mathrm{H}, \mathrm{dd}, J_{\mathrm{HH}}=7.7 \mathrm{~Hz}, 2.4 \mathrm{~Hz}, \mathrm{H} 3\right), 2.46$ $\left(9 \mathrm{H}, \mathrm{s}, \mathrm{CH}_{3}\right) .{ }^{31} \mathrm{P}\left\{{ }^{1} \mathrm{H}\right\} \mathrm{NMR}\left(\mathrm{CD}_{3} \mathrm{CN}, 161.99 \mathrm{MHz}\right), \delta[\mathrm{ppm}]=45.3$ (s). ${ }^{13} \mathrm{C}\left\{{ }^{1} \mathrm{H}\right\} \mathrm{NMR}\left(\mathrm{CD}_{3} \mathrm{CN}, 100.63 \mathrm{MHz}\right), \delta[\mathrm{ppm}]=211.8\left(\mathrm{~d}, J_{\mathrm{CP}}=\right.$ $26 \mathrm{~Hz}$, trans-CO), $206.3\left(\mathrm{~d}, J_{\mathrm{CP}}=9.2 \mathrm{~Hz}\right.$, cis-CO), $159.4\left(\mathrm{~d}, J_{\mathrm{CP}}=\right.$ 17.7 Hz, C2), 157.6 (d, $\left.J_{\mathrm{CP}}=59.7 \mathrm{~Hz}, \mathrm{C} 6\right), 136.4\left(\mathrm{~d}, J_{\mathrm{CP}}=5.1 \mathrm{~Hz}\right.$ C4), $124.7\left(\mathrm{~d}, J_{\mathrm{CP}}=15.0 \mathrm{~Hz}, \mathrm{C} 3\right), 123.6\left(\mathrm{~d}, J_{\mathrm{CP}}=1.7 \mathrm{~Hz}, \mathrm{C} 5\right), 23.2$ (s, C7). Elemental analysis, calcd. for $\left[\mathrm{Mo}(\mathrm{CO})_{5}\left\{\mathrm{P}(6-\mathrm{Me}-2-\mathrm{py})_{3^{-}}\right.\right.$ $\mathrm{K}^{1} P$ \}] (17), C 50.8, H 3.3, N 7.7; found C 50.6, H 3.1, N 8.1. ATRIR, v $\left[\mathrm{cm}^{-1}\right]=3441$ (br), $3054(\mathrm{w}), 2926$ (w), 2070 (s, CO stretch), 1991 (s, CO stretch), 1931 (br, CO stretch), 1913 (s, CO stretch), $1579(\mathrm{~m}), 1559(\mathrm{~m}), 1444(\mathrm{~s}), 1375(\mathrm{w}), 1248(\mathrm{w}), 1174(\mathrm{w}), 1135$ (w), $1092(w), 1038(w), 984(w), 899(w), 865(w), 785(m), 735$ (m). MS (ESI, +) m/z: 825.1408, calcd. 825.1406 (0.24 ppm error), $\left[\mathrm{M}+\mathrm{P}(6 \mathrm{Me}-2-\mathrm{py})_{3}\right]^{+}$. Due to the instability of $\mathbf{1 7}$ towards air and moisture, small impurities can be found in the NMR spectra of 17. This fact also explains the slight deviations in the elemental analysis results.

\section{Synthesis of cis-[Mo(CO) $\left.{ }_{4}\left\{\mathrm{P}(6-\mathrm{Br}-2-\mathrm{py})_{3}-\mathrm{K}^{1} \mathrm{P}\right\}_{2}\right](19)$}

A mixture of $\left[\mathrm{Mo}(\mathrm{CO})_{6}\right](0.11 \mathrm{~g}, 0.40 \mathrm{mmol})$ and $\mathrm{Me}_{3} \mathrm{NO}(30 \mathrm{mg}$ $0.40 \mathrm{mmol}$ ) in $3 \mathrm{ml}$ of acetonitrile was stirred for $30 \mathrm{~min}$ at room temperature. Ligand $\mathbf{3}(0.20 \mathrm{~g}, 0.40 \mathrm{mmol})$ in $7 \mathrm{ml}$ of acetonitrile was added to the yellow solution. The resulting brown solution with white precipitate was stirred for 5 days. The precipitate was filtered off and crystals were grown overnight from the saturated MeCN solution. Yield: $64 \mathrm{mg}, 0.53 \mathrm{mmol}, 13 \% .{ }^{1} \mathrm{H}$ $\operatorname{NMR}\left(\mathrm{CDCl}_{3}, 400.16 \mathrm{MHz}\right), \delta[\mathrm{ppm}]=7.66\left(3 \mathrm{H}, \mathrm{d}, J_{\mathrm{HH}}=7.5 \mathrm{~Hz}\right.$, $\mathrm{H} 5), 7.40\left(3 \mathrm{H}, \mathrm{t}, J_{\mathrm{HH}}=7.8 \mathrm{~Hz}, \mathrm{H} 4\right), 7.27\left(3 \mathrm{H}, \mathrm{d}, J_{\mathrm{HH}}=8 \mathrm{~Hz}, \mathrm{H} 3\right)$. ${ }^{31} \mathrm{P}\left\{{ }^{1} \mathrm{H}\right\} \operatorname{NMR}\left(\mathrm{CDCl}_{3}, 161.99 \mathrm{MHz}\right), \delta[\mathrm{ppm}]=50.3(\mathrm{~s}) .{ }^{13} \mathrm{C}\left\{{ }^{1} \mathrm{H}\right\}$ $\mathrm{NMR}\left(\mathrm{CDCl}_{3}, 100.63 \mathrm{MHz}\right), \delta[\mathrm{ppm}]=208.2(\mathrm{~s}, \mathrm{CO}), 160.19$ (d, $J_{\mathrm{CP}}$ $=51.7 \mathrm{~Hz}, \mathrm{C} 2), 141.5\left(\mathrm{t}, J_{\mathrm{CP}}=7.4 \mathrm{~Hz}, \mathrm{C} 6\right), 137.8(\mathrm{~s}, \mathrm{C} 4), 128.4(\mathrm{t}$, $\left.J_{\mathrm{CP}}=9.8 \mathrm{~Hz}, \mathrm{C5}\right), 128.0(\mathrm{~s}, \mathrm{C3})$. Elemental analysis, calcd. for cis- $\left[\mathrm{Mo}(\mathrm{CO})_{4}\left\{\mathrm{P}(6-\mathrm{Br}-2-\mathrm{py})_{3}-\mathrm{K}^{1} \mathrm{P}\right\}_{2}\right], \mathrm{C} 33.7, \mathrm{H} 1.5, \mathrm{~N}$ 6.9; found $\mathrm{C}$ 34.0, H 1.5, N 7.1. ATR-IR, v [ $\left.\mathrm{cm}^{-1}\right]=3437$ (br), $3082(\mathrm{w}), 2920$ (w), 2361 (w), 2029 (s, CO stretch), 1923 (s, CO stretch), 1880 (s, CO stretch), $1544(\mathrm{~s}), 1415(\mathrm{~s}), 1379(\mathrm{~m}), 1168(\mathrm{~m}), 1112(\mathrm{~s})$, $1080(\mathrm{~m}), 980(\mathrm{~m}), 905(\mathrm{w}), 790(\mathrm{~m}), 760(\mathrm{~m}), 727(\mathrm{~m}) . \mathrm{MS}$ (ESI, +) m/z: 1236.4835, calcd. $1236.4856(-1.7$ ppm error), [M+Na] .

\section{Computational Details}

All calculations were carried out with the ORCA package (version 4.0.0.1) in the gas phase. ${ }^{60,61}$ For all ORCA calculations, atom-pairwise dispersion corrections with the Becke-Johnson damping scheme (D3BJ) were utilised. ${ }^{62,63}$ Density fitting techniques, also called resolution-of-identity approximation (RI), were used for GGA calculations. Geometry optimisation of the $\left[\mathrm{Ni}(\mathrm{CO})_{3} \mathrm{~L}\right]$ complexes were carried out employing the TPSS ${ }^{56}$ functional in conjunction with the def2-TZVP 57,58 basis set. Frequency calculations of the optimised structure at the same level of theory were utilised to prove the absence of imaginary frequencies and to determine the carbonyl stretching frequencies. The meta-GGA functional was chosen, since it showed excellent agreement of the symmetric $A_{1} C O$ stretch in $\left[\mathrm{Ni}(\mathrm{CO})_{3}\left(\mathrm{P}^{t} \mathrm{Bu}_{3}\right)\right]$ with that reported in the literature $\left(\mathrm{v}\left[\mathrm{cm}^{-1}\right]=\right.$ $2056,{ }^{6}$ CO stretch, ESI, Table S3).

\section{Single-crystal $X$-ray crystallography}

Single-crystal $\mathrm{X}$-ray crystallography was carried out with a Bruker D8-Quest Photon-100 diffractometer using an Incoatec I $\mu \mathrm{S}$ Cu microsource ( $\mathrm{Cu}-\mathrm{K} \alpha \lambda=1.5418 \AA$ ) or an Oxford Xcalibur $\mathrm{S}$ CCD diffractometer (Mo-K $\alpha, \lambda=0.71073 \AA$ ) $)$. For the Bruker machine, data collection and reduction were carried out using the APEX2/APEX3 and SAINT packages, ${ }^{64}$ whereas for the Oxford Xcalibur diffractometer data were collected and processed with CrysAlis Pro. ${ }^{65}$ Structures were solved by direct methods using SHELXS ${ }^{66}$ or SHELXT ${ }^{67}$ and refined using fullmatrix least squares on $\mathrm{F}^{2}$ using Crystals ${ }^{68}$ or SHELXL-2014 ${ }^{69}$ and the graphical interface shelXle. ${ }^{70}$ Absorption effects were corrected on the basis of multiple equivalent reflections using SADABS ${ }^{71}$ or SCALE3 ABSPACK. ${ }^{72}$ In general, carbon-bound hydrogen atoms were included in idealised positions and refined using a riding model. Pictures were generated in Diamond. ${ }^{73}$ Crystallographic details are given in the ESI (Table S1 and S2). CCDC 1983662-1983667.

\section{Conflicts of interest}

There are no conflicts to declare.

\section{Acknowledgements}


Financial support by the Studienstiftung des deutschen Volkes (doctoral fellowship for S. H.) the Leverhulme Trust (D. S. W., R.G.-R., postdoctoral research grant for A. L. C.) and the Spanish Ministry of Science, Innovation and Universities (MCIU) (PGC2018-096880-A-I00, MCIU/AEI/FEDER, UE) is gratefully acknowledged. R.G.-R. acknowledges the Spanish MINECO/AEI and the European Union (ESF) for a Ramon y Cajal contract (RYC2015-19035).

\section{Notes and references}

1 D. G. Gusev, Organometallics, 2009, 28, 763-770.

2 W. Strohmeier and F.-J. Müller, Chem. Ber., 1967, 100, 2812-2821. A. G. Orpen and N. G. Connelly, Organometallics, 1990, 9 1206-1210.

C. A. Tolman, Chem. Rev., 1977, 77, 313-348.

D. R. Anton and R. H. Crabtree, Organometallics, 1983, 2, 621-627.

O. Kühl, Coord. Chem. Rev., 2005, 249, 693-704.

T. A. Magee, C. N. Matthews, T. S. Wang and J. H. Wotiz, J. Am. Chem. Soc., 1961, 83, 3200-3203.

A. M. Bond, S. W. Carr and R. Colton, Organometallics, 1984, 3, 541-548. Chem. Soc., 1967, 89, 5573-5577. H. J. W.D. and R. C. Taylor, Inorg. Chem., 1963, 2, 723-727. F. A. Cotton, Inorg. Chem., 1964, 3, 702-711. E. C. Alyea, G. Ferguson and A. Somogyvari, Organometallics, 1983, 2, 668-674. J. Dalton, I. Paul, J. G. Smith and F. G. A. Stone, J. Chem. Soc. A, 1968, 1195-1199.

S. P. Nolan and C. D. Hoff, J. Organomet. Chem., 1985, 290, 365-373.

S. S. Woodard, R. J. Angelici and B. D. Dombek, Inorg. Chem., 1978, 17, 1634-1639.

R. J. Angelici and S. M. D. Malone, Inorg. Chem., 1967, 6, 1731-1736.

M. Bancroft, L. Dignard-Bailey and R. J. Puddephatt, Inorg. Chem., 1986, 25, 3675-3680.

R. A. Brown and G. R. Dobson, Inorg. Chim. Acta, 1972, 6, 65-71.

W. Strohmeier and J. F. Guttenberger, Chem. Ber., 1964, 97, 1871-1876.

W. Strohmeier and F.-J. Müller, Z. Naturforsch., 1967, 22b, 451-452.

H. Inoue, T. Nakagoma, T. Kuroiwa, T. Shirai and E. Fluck, $Z$. Naturforsch., 1987, 42B, 573-578.

R. T. Smith and M. C. Baird, Inorg. Chim. Acta, 1982, 62, 135-139.

M. Herberhold, K. Leonhard, U. Wagner, F. E. Wagner and J. Danon, J. Chem. Soc., Dalton Trans., 1979, 654-657.

D. J. Darensbourg, H. H. I. Nelson and C. C. Hyde, Inorg. Chem., 1974, 13, 2135-2145.

D. Cunningham, Z. Goldschmidt, H. F. Gottlieb and D. Hezroni-Langerman, Inorg. Chem., 1991, 30, 4683-4685. J. A. S. Howard, J. D. Lovatt, P. McArdle, D. Cunningham, E.
Maimone, H. E. Gottlieb and Z. Goldschmidt, Inorg. Chem. Commun., 1998, 118-120.

R. L. Collins and R. Petit, J. Chem. Phys., 1963, 39, 34333435.

S. Otto and A. Roodt, Inorg. Chim. Acta, 2004, 357, 1-10. S. Serron, J. Huang and S. P. Nolan, Organometallics, 1998, 17, 534-539.

A. Roodt, S. Otto and G. Steyl, Coord. Chem. Rev., 2003, 245, 121-137.

L. F. Szczepura, L. M. Witham and K. J. Takeuchi, Coord. Chem. Rev., 1998, 174, 5-32.

P. Espinet and K. Soulantica, Coord. Chem. Rev., 1999, 193195, 499-556.

A. P. Sadimenko, Adv. Heterocycl. Chem., 2011, 104, 391475.

A. V. Artem'ev, A. V. Kashevskii, A. S. Bogomyakov, A. Y. Safronov, A. O. Sutyrina, A. A. Telezhkin and I. V. Sterkhova, Dalton Trans., 2017, 46, 5965-5975. S. Hanf, R. García-Rodríguez, A. D. Bond, E. Hey-Hawkins and D. S. Wright, Dalton Trans., 2016, 45, 276-283. S. Hanf, R. García-Rodríguez, S. Feldmann, A. D. Bond, E. Hey-Hawkins and D. S. Wright, Dalton Trans., 2017, 46, 814-824.

F.-W. Lee, M. Chi-Wang Chan, K.-K. Cheung and C.-M. Che, J. Organomet. Chem., 1998, 563, 191-200.

J. A. Casares, P. Espinet, R. Hernando, G. Iturbe, F. Villafañe, D. D. Ellis and A. G. Orpen, Inorg. Chem., 1997, 36, 44-49.

P. Espinet, P. Gómez-Elipe and F. Villafañe, J. Organomet. Chem., 1993, 450, 145-150. C.-Y. Y. Kuo, Y.-S. S. Fuh, J.-Y. Y. Shiue, S. J. Yu, G.-H. Lee and S.-M. Peng, J. Organomet. Chem., 1999, 588, 260-267. D. Lionetti, V. W. Day, B. Lassalle-Kaiser and J. D. Blakemore, Chem. Commun., 2018, 54, 1694-1697. K. T. Horak, D. G. VanderVelde and T. Agapie, Organometallics, 2015, 34, 4753-4765. V. K. Jha, G. Mani, Y. R. Davuluri and A. Anoop, Dalton Trans., 2017, 46, 1840-1847.

P. Espinet, R. Hernando, G. Iturbe, F. Villafañe, A. G. Orpen and I. Pascual, Eur. J. Inorg. Chem., 2000, 1031-1038.

G. Zhang, J. Zhao, G. Raudaschl-Sieber, E. Herdtweck and F. E. Kühn, Polyhedron, 2002, 21, 1737-1746. A. L. Morris and J. T. York, J. Chem. Educ., 2009, 86, 14081411.

F. R. Hartley, Chem. Soc. Rev., 1973, 163-179. A. Kovacs and G. Frenking, Organometallics, 2001, 20, 2510-2524.

L. Hirsivaara, M. Haukka and J. Pursiainen, Eur. J. Inorg. Chem., 2001, 2255-2262.

50 L. Hirsivaara, M. Haukka and J. Pursiainen, Inorg. Chem. Commun., 2000, 3, 508-510.

51 A. J. Plajer, A. L. Colebatch, M. Enders, Á. García-Romero, A. D. Bond, R. García-Rodríguez and D. S. Wright, Dalton Trans., 2018, 47, 7036-7043. D. Ülkü, M. N. Tahir and S. Özkar, Acta Crystallogr. C, 1997, C53, 185-187.

F. A. Cotton, D. J. Darensbourg and W. H. Ilsley, Inorg. 
Chem, 1981, 20, 578-583.

54 F. A. Cotton, D. J. Darensbourg, S. Klein and B. W. S. Kolthammer, Inorg. Chem, 1982, 21, 294-299.

55 L. Perrin, E. Clot, O. Eisenstein, J. Loch and R. H. Crabtree, Inorg. Chem., 2001, 40, 5806-5811.

56 J. Tao, J. P. Perdew, V. N. Staroverov and G. E. Scuseria, Phys. Rev. Lett., 2003, 91, 146401-1-146401-4.

57 F. Weigend and R. Ahlrichs, Phys. Chem. Chem. Phys., 2005, 7, 3297-3305.

58 F. Weigend, Phys. Chem. Chem. Phys., 2006, 8, 1057-1065.

59 R. K. Harris, E. D. Becker, S. M. Cabral De Menezes, R. Goodfellow and P. Granger, Concepts Magn. Res., 2002, 14, 326.

60 F. Neese, WIREs Comput. Mol. Sci., 2018, 8, e1327.

61 F. Neese, WIREs Comput. Mol. Sci., 2012, 2, 73-78.

62 S. Grimme, J. Antony, S. Ehrlich and H. Krieg, J. Chem. Phys., 2010, 132, 154104-154104.

63 S. Grimme, S. Ehrlich and L. Goerigk, J. Comp. Chem., 2011, 32, 1456-1465.

64 APEX, SAINT, Bruker, Bruker AXS Inc., Madison, Wisconsin, USA, 2012.

65 CrysAlis PRO, Agilent, Agilent Technologies Ltd, Yarnton, Oxfordshire, England, 2014.

66 G. M. Sheldrick, Acta Crystallogr. A, 2008, 64, 112-122.

67 G. M. Sheldrick, Acta Crystallogr. A, 2015, 71, 3-8.

68 P. W. Betteridge, J. R. Carruthers, R. I. Cooper, K. Prout and

D. J. Watkin, J. Appl. Cryst., 2003, 36, 1487.

69 G. M. Sheldrick, Acta Crystallogr. C, 2015, 71, 3-8.

70 C. B. Hübschle, G. M. Sheldrick and B. Dittrich, J. Appl. Cryst., 2011, 44, 1281-1284.

71 SADABS, Bruker, Bruker AXS Inc., Madison, Wisconsin, USA, 2001.

72 SCALE3 ABSPACK, Oxford Diffraction, Oxford Diffraction Ltd, Abingdon, Oxfordshire, England, 2006.

73 Diamond-Crystal and Molecular Structure Visualization, $\mathrm{H}$. Putz, K. Brandenburg, Crystal Impact GbR, Bonn, Nordrhein-Westfalen, Germany, 1999. 